\title{
Rietveld Refinement of the Crystal Structure of Hydroxyapatite Using X-ray Powder Diffraction
}

\author{
A. El Yacoubi ${ }^{1}$, A. Massit ${ }^{1}$, S. El Moutaoikel ${ }^{1}$, A. Rezzouk ${ }^{2}$, B. Chafik El Idrissi ${ }^{1{ }^{*}}$ \\ ${ }^{1}$ Team Materials Surfaces Interfaces, Laboratory Materials and Energitics, Fac of Sciences, University Ibn Tofail, kenitra, Morocco \\ ${ }^{2}$ LPS, Fac. des Sciences Dhar El Mehraz, BP 1796, Atlas FES, Morocco \\ *Corresponding author: chidrissi@yahoo.fr
}

\begin{abstract}
The stoichiometric hydroxyapatite, $\mathrm{Ca}_{10}\left(\mathrm{PO}_{4}\right)_{6}(\mathrm{OH})_{2}$ is prepared by an aqueous precipitation method at room temperature, the main reactants were $\mathrm{Ca}(\mathrm{OH})_{2}$ and $\mathrm{H}_{3} \mathrm{PO}_{4}$ without addition of ammonia solution. The sample was analyzed by Fourier transformed infrared spectroscopy (FTIR) which reveals the presence of a small amount of carbonate due to absorbance of carbon dioxide from the air during synthesis process. The crystal structure was carried out by X-ray powder diffraction data and the Rietveld method using FullPROF software. We confirmed that this material has a hexagonal structure (space group P63/m; $\mathrm{Z}=1$ ). Unit-cell parameters with higher precision $(\mathrm{a}=\mathrm{b}$ $=9.4159(4) \AA, c=6.8819(3) \AA, \alpha=\beta=90^{\circ}$; and $\left.\gamma=120^{\circ}\right)$.
\end{abstract}

Keywords: hydroxyapatite, infrared spectroscopy, X-ray powder diffraction, Rietveld refinement

Cite This Article: A. El Yacoubi, A. Massit, S. El Moutaoikel, A. Rezzouk, and B. Chafik El Idrissi, "Rietveld Refinement of the Crystal Structure of Hydroxyapatite Using X-ray Powder Diffraction." American Journal of Materials Science and Engineering, vol. 5, no. 1 (2017): 1-5. doi: 10.12691/ajmse-5-1-1.

\section{Introduction}

Although single-crystal and powder X-ray diffraction patterns contain essentially the same information, in the single-crystal case this information is distributed in three-dimensional reciprocal space, whereas in the powder case the three-dimensional diffraction data are effectively compressed into one dimension (intensity versus diffraction angle 2 $\theta$ ) as a consequence of the random orientational distribution of the crystallites in the powder sample. Such compression usually results an extensive overlap of peaks in a powder X-ray diffraction pattern. As a result, the process of extracting intensity data from the powder X-ray diffraction pattern can be unreliable and leads to difficulties in attempting to carry out structure solution using such data.

In orthopedic and dental surgeries fields, the most commonly used material for coatings is hydroxyapatite (HAp). The HAp $\mathrm{Ca}_{10}\left(\mathrm{PO}_{4}\right)_{6}(\mathrm{OH})_{2}$ is found in natural human hard tissue and considered as the main inorganic component of bone and teeth [1,2,3]. It has been proven that synthetic hydroxyapatite exhibits properties such as osteoconductivity and osteoinductivity which stimulate bone regeneration [4]. Due to its excellent biocompatibility, the HAp has been widely used as a coating material for implanted devices [5,6]. Another important characteristic of HAp is its biodegradability. Previous studies [7-12] have shown that hydroxyapatite tends not to trigger a response from the immune system, embedding itself successfully in the surrounding tissue and degrading over time as the host tissue begins to regenerate.
The hydroxyapatite structure was published nearly simultaneously by Náray-Szabó [13] and Mehmel [14] in 1930. it possesses a hexagonal structure with a $P 63 / \mathrm{m}$ space group and cell dimensions $\mathrm{a}=\mathrm{b}=9.42 \AA$, and $\mathrm{c}=6.88 \AA$, where $\mathrm{P}_{3} / \mathrm{m}$ refers to a space group with a six-fold symmetry axis with a threefold helix and a mirror plane [15], It has an exact stoichiometric Ca/P ratio of 1.67 .

The aim of this study was to undertake an X-ray powder diffraction study of a nanometer scale crystalline HAp powder synthesized by a novel method.

\section{Materials and Methods}

\subsection{Simple Preparation}

The hydroxyapatite sample is prepared via an aqueous precipitation reaction of $\mathrm{Ca}(\mathrm{OH})_{2}$ and $\mathrm{H}_{3} \mathrm{PO}_{4}$ as described in our previous paper [16]. In brief, the pure HAp was prepared by a precipitation method at room temperature (RT). After the total addition of the $\mathrm{H}_{3} \mathrm{PO}_{4}$ solution, the $\mathrm{pH}$ remained greater than 10 (no ammonia was therefore added) and the suspension was continuously agitated for an additional $2 \mathrm{~h}$ at the same medium temperature and then matured over a period of $48 \mathrm{~h}$ at RT. This matured suspension was decanted and subjected to thermal treatment at $90^{\circ} \mathrm{C}$ for $24 \mathrm{~h}$ and ground to a fine powder in an agate mortar. The resulting oven-dried precipitate is calcined at $900^{\circ} \mathrm{C}$ in a dry air atmosphere in order to improve its crystallinity.

XRD measurements were performed for phase identification and phase purity with the use of a Shimadzu 6100 diffractometer equipped with a diffracted beam 
monochromator and $\mathrm{CuK} \alpha$ wavelength. A single HAp phase (card \#9-432) was identified in all specimens by using the ICDD (International Center for Diffraction Data) data bank.

The functional groups present in the prepared powder calcined at $900^{\circ} \mathrm{C}$ were identified by FTIR (Vertex 70 Spectrometer). To perform a IR spectrum, 1\% of the powder was mixed and ground with $99 \% \mathrm{KBr}$. Tablets of $10 \mathrm{~mm}$ diameter for FTIR measurements were prepared by pressing the powder mixture under 5 tons for 2 min and the spectrum was taken in the range of 400 to $4000 \mathrm{~cm}^{-1}$ with resolution 4 and 128 times scanning.

\subsection{Rietveld Refinement Theory}

A detailed description of the mathematical procedures implemented in the Rietveld analysis has been earlier reported $[17,18,19,20]$. Here, we give brief details of the analysis of experimental powder diffraction patterns that we've done. The crystal structure characterization of the synthesized sample has been made by employing the Rietveld's whole-profile fitting method using FullPROF software [21].

The experimental profiles were fitted with the most suitable pseudo-Voigt analytical function. For both the $\mathrm{K} \alpha 1$ and $\mathrm{K} \alpha 2$ profiles, the line broadening function $\mathrm{B}(2 \theta)$ may be represented by the pseudo-Voigt function:

$$
\mathrm{pV}(\mathrm{x})=\eta \mathrm{L}(\mathrm{x})+(1-\eta) \mathrm{G}(\mathrm{x}) .
$$

The $\mathrm{L}(\mathrm{x})$ and $\mathrm{G}(\mathrm{x})$ are, respectively, the Lorentzian and Gaussian components. Considering the integrated intensity of the peaks as a function of structural parameters only, the Marquardt least-squares procedures were adopted for minimization of the difference between the observed and simulated powder diffraction patterns. The minimization was carried out using the reliability index parameter such as the residuals for the weighted pattern Rwp, the pattern Rp, Braggs factor RBragg, structure factor RF, and goodness of fit $\chi^{2}$. All these parameters were used as numerical criteria of the quality of the fit of calculated to experimental diffraction data and are represented by the following relations [22]:

$$
\begin{gathered}
\mathrm{R}_{\mathrm{wp}}=100 \cdot\left[\sum_{i} \mathrm{w}_{\mathrm{i}}\left(\mathrm{y}_{\mathrm{i}(\text { obs })}-\mathrm{y}_{\mathrm{i}(\mathrm{cal})}\right)^{2} / \sum_{i} \mathrm{w}_{\mathrm{i}} \mathrm{y}_{\mathrm{i}(\text { obs })}\right]^{1 / 2} \\
\mathrm{Rp}=100 \sum_{i}\left|\mathrm{y}_{\mathrm{i}(\text { obs })}-\mathrm{y}_{\mathrm{i}(\mathrm{cal})}\right| / \sum_{i} \mathrm{y}_{\mathrm{i}(\mathrm{obs})} \\
\mathrm{R}_{\mathrm{B}}=100 \sum_{i}\left|\mathrm{I}_{\mathrm{i}(\mathrm{obs})}-\mathrm{I}_{\mathrm{i}(\mathrm{cal})}\right| / \sum_{i} \mathrm{I}_{\mathrm{i}(\mathrm{obs})} \\
\mathrm{R}_{\exp }=100\left[(\mathrm{~N}-\mathrm{P}+\mathrm{C}) / \sum_{i} \mathrm{w}_{\mathrm{i}} \mathrm{y}_{\mathrm{i}(\mathrm{obs})}\right]^{1 / 2} \\
\chi^{2}=\left[\mathrm{R}_{\mathrm{wp}} / \mathrm{R}_{\exp }\right]^{2}
\end{gathered}
$$

where $\mathrm{y}_{\mathrm{i}(\mathrm{obs})}$ is the experimental intensities, $\mathrm{y}_{\mathrm{i}(\mathrm{cal})}$ is the calculated intensities, $\mathrm{w}_{\mathrm{i}}=\left(1 / \mathrm{y}_{\mathrm{i}(\mathrm{obs})}\right)$ is the weight experimental observations, $\mathrm{N}$ is the number of experimental observations, $\mathrm{P}$ is the number of fitting parameters, $\mathrm{C}$ number of constraints and I is the integrated intensity. The goodness of fit indicator (GOF) is established by comparing $\mathrm{R}_{\mathrm{wp}}$ with the expected error $\mathrm{R}_{\text {exp }}$. This leads to the value of goodness of fit:

$$
\mathrm{GOF}=\mathrm{R}_{\mathrm{wp}} / \mathrm{R}_{\mathrm{exp}} \text {. }
$$

\section{Results and Discussions}

The X-ray powder diffraction pattern of the HAp sample is shown in Figure 1. The XRD pattern shows the characteristic peaks of hydroxyapatite, according to the International Center for Diffraction Data database, ICDD-PDF 9-0432. The XRD pattern indicates the presence of a majority phase corresponding to the hexagonal singony - $\mathrm{P} 6_{3 / \mathrm{m}}$ space group associated to pure crystalline nanometer sized HAp. In addition, no other minority phase has been detected, within the X-ray detection limits of $\sim 2 \%$.

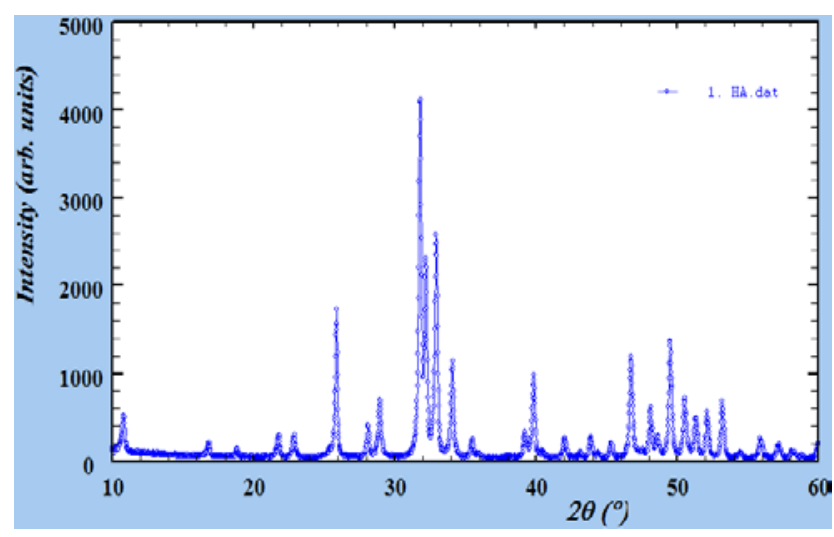

Figure 1. X-ray powder diffraction pattern of Hap sample

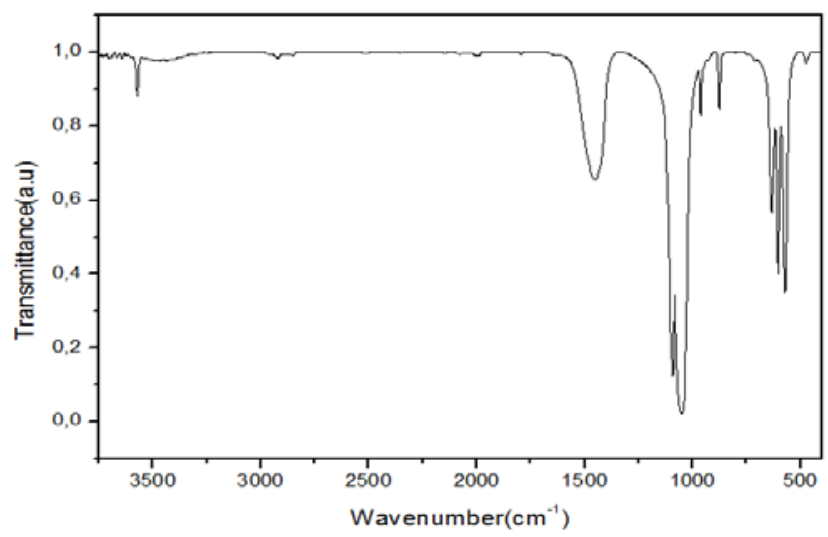

Figure 2. FTIR of as-synthesized hydroxyapatite sample

The functional groups present in the prepared sample were investigated by FT-IR studies (Figure 2). The spectra registered for the hydroxyapatite showed the apatite characteristic bands. The presence of phosphate group $\mathrm{PO}_{4}{ }^{3-}$ is highlighted by the $474 \mathrm{~cm}^{-1}$ band associated to the $v 2$ double degenerated bending mode and the bands found at 570 and $603 \mathrm{~cm}^{-1}$ characteristic to the $v 4$ vibration mode. Furthermore, the band registered at $962 \mathrm{~cm}^{-1}$ is evidence of the $v 1$ non-degenerated symmetric stretching mode of the P-O bond and the bands found at 1040 and $1098 \mathrm{~cm}^{-1}$ are associated to the $v 3$ vibration mode of the functional group. Sharp bands at $3573 \mathrm{~cm}^{-1}$ and $633 \mathrm{~cm}^{-1}$ correspond to stretching and vibrational modes of hydroxyl vibrations, 
respectively. On the other hand, the $\mathrm{CO}_{3}{ }^{2-}$ functional group is highlighted by the presence of several vibration bands. The band found at around $875 \mathrm{~cm}^{1}$ can be characteristic to the $v 2$ vibration mode and the stretching vibrations of the $\mathrm{CO}_{3}{ }^{2-}$ group are highlighted by the band in the region 1400 and $1500 \mathrm{~cm}^{-1}$. The carbonate presence in the specimens is due to absorbance of carbon dioxide from the air during synthesis of the sample and it has been reported by others $[23,24]$.

\subsection{Peaks' Search and the Initial Structure Determination}

The refinements were performed using the computer program FullProf which has been mainly developed to perform Rietveld analysis. The average intensity profile Analysis using the peak-search tool in the program WinPLOTR [25] yielded 28 peaks between $20^{\circ}$ and $60^{\circ}$ in $2 \theta$ range. These peak positions were used as input for the program DICVOL [26] which is an automatic program for finding the unit cell. As a result, its basic structure is a Hexagonal system with lattice parameters $\mathrm{a}=\mathrm{b}=9.4153$ $\AA$ and $\mathrm{c}=6.8822 \AA$. Determination of the most likely space groups was achieved by the program CHECKGROUP. The best solution resulted in space group is $P 6_{3} / \mathrm{m}$.

\subsection{Refinement of XRD Data}

The inherent parameters determined by the standard data and other experimental parameters were used as input data in the program FULLPROF, the atomic positions reported in the literature $[27,28]$ were used for the initial values in the first preliminary refinement. The pseudoVoigt profile function of Thompson, Cox and Hastings [29] was employed to model the peak shape of the Bragg reflections. The refinement procedure was started by refining: the scale factor, zero point of detector, $1^{\text {st }}$ background parameter (polynomial function of sixth order) and lattice parameters; then gradually more parameters were opened; the peak profile (pseudo-Voigt) parameters, atomic coordinates and isotropic displacement parameters B. In the final step the individual anisotropic thermal parameters (ATPs) could be improved. Attempts to refine the ATPs of the hydrogen atom were not successful, then Isotropic displacement parameter is Kept fixed at the value 1.5. The structure refinement was stable at all stages and converged rapidly to the results summarized in Table 1.

Table 1. Lattice parameters and agreement factors for $\mathrm{HA}$

\begin{tabular}{ll}
\hline Unit cell parameters & $\begin{array}{l}\mathrm{a}=\mathrm{b}=9,4159 \AA ; \mathrm{c}=6,8819 \AA, \alpha=\beta=90^{\circ} ; \\
\gamma=120^{\circ}\end{array}$ \\
\hline Number of space group & 176 \\
Hermann-Manguin symbol & $\mathrm{P}_{3} / \mathrm{m}$ \\
& \\
Volume $\left(\AA^{3}\right)$ & 528,400 \\
Bragg R-factor & 1,82 \\
$\mathrm{R}_{\mathrm{f}}$ - factor & 1,50 \\
R factors & $\mathrm{R}_{\mathrm{p}}=9.99 ; \mathrm{R}_{\mathrm{wp}}=12.8 ; \mathrm{R}_{\exp }=9.43$ \\
Chi squared $\chi^{2}$ & 1,84 \\
GOF & 1.35 \\
\hline
\end{tabular}

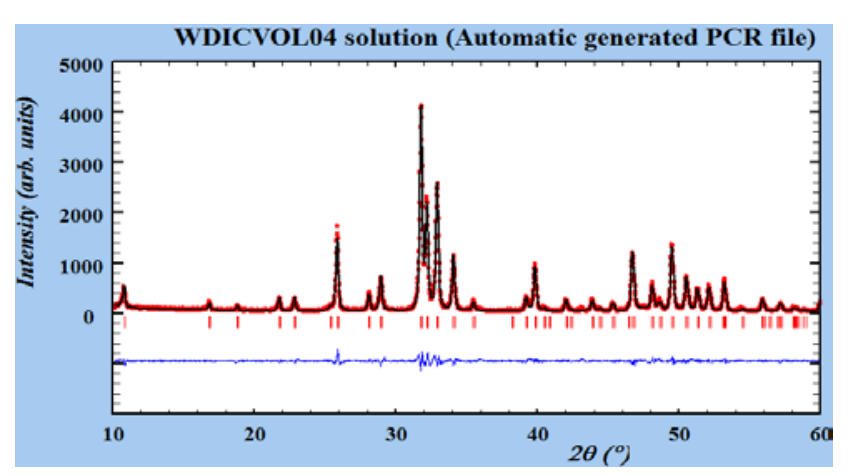

Figure 3. Final Rietveld refinement of the HAp sample: calculated (black solid line), experimental (red dots mark) X-ray powder diffraction pattern and difference curve (blue)

Table 2. Atomic coordinates and occupancies for sample HAp

\begin{tabular}{|c|c|c|c|c|c|c|}
\hline Atom & Wyckoff position & $\mathrm{x}$ & $\mathrm{y}$ & $\mathrm{z}$ & Occ & $\mathrm{B}_{\mathrm{ISO}}$ \\
\hline O1 & $6 \mathrm{~h}$ & 0.3259 & 0.48244 & 0.25000 & 5.9154 & 2.4421 \\
\hline $\mathrm{O} 2$ & $6 \mathrm{~h}$ & 0.5839 & 0.46367 & 0.25000 & 5.8946 & 1.3273 \\
\hline $\mathrm{O} 3$ & $12 \mathrm{i}$ & 0.3381 & 0.25338 & 0.06712 & 12.1170 & 1.6715 \\
\hline $\mathrm{O}(\mathrm{H})$ & $4 \mathrm{e}$ & 0.0000 & 0.00000 & 0.22352 & 2.0015 & 3.3422 \\
\hline $\mathrm{H}$ & $4 e$ & 0.0000 & 0.00000 & 0.16450 & 1.9402 & 1.0004 \\
\hline Ca1 & $4 \mathrm{f}$ & 0.3333 & 0.66667 & 0.00112 & 4.0060 & 1.8642 \\
\hline $\mathrm{Ca} 2$ & $6 h$ & 0.2484 & 0.99304 & 0.25000 & 5.9143 & 1.2372 \\
\hline $\mathrm{P}$ & $6 \mathrm{~h}$ & 0.3980 & 0.36911 & 0.25000 & 5.9393 & 1.0943 \\
\hline
\end{tabular}

Table 3. Anisotropic displacement parameters for HAp sample

\begin{tabular}{|c|c|c|c|c|c|c|}
\hline Atom & $\mathrm{U}_{11}$ & $\mathrm{U}_{22}$ & $\mathrm{U}_{33}$ & $\mathrm{U}_{12}$ & $\mathrm{U}_{13}$ & $\mathrm{U}_{23}$ \\
\hline O1 & 0.00879 & 0.01597 & 0.00391 & 0.01477 & 0.00000 & 0.00000 \\
\hline $\mathrm{O} 2$ & 0.01400 & 0.00091 & 0.00008 & 0.00501 & 0.00000 & 0.00000 \\
\hline O3 & 0.01300 & 0.00530 & 0.00078 & 0.01042 & 0.00116 & 0.00769 \\
\hline $\mathrm{O}(\mathrm{H})$ & 0.00545 & 0.00545 & 0.03762 & 0.00273 & 0.00000 & 0.00000 \\
\hline Ca1 & 0.00763 & 0.00763 & 0.00809 & 0.00381 & 0.00000 & 0.00000 \\
\hline $\mathrm{Ca} 2$ & 0.00482 & 0.00151 & 0.01071 & 0.00103 & 0.00000 & 0.00000 \\
\hline $\mathrm{P}$ & 0.00367 & 0.00325 & 0.00762 & 0.00215 & 0.00000 & 0.00000 \\
\hline
\end{tabular}


The calculated and experimental diffraction profiles are shown in Figure 3 together with the difference curve obtained after the final refinement, the dots mark is the experimental pattern and the solid line is the calculated diffraction pattern. The lower trace is the difference between observed and calculated patterns, and the vertical lines mark the positions of the calculated Bragg peaks. It is worth noting the good agreement between both of them. Atomic coordinates, occupancies, lattice parameters and agreement factors for HAp are collected in Table 2. The anisotropic displacement parameters for Hap are listed in Table 3.

The maximum theoretical occupancy for $\mathrm{O}$ and $\mathrm{H}$ at the 2a position is 2. Sample HAp shows 2 and 1.94 for $\mathrm{O}$ and $\mathrm{H}$, respectively. Considering that the $\mathrm{H}$ atoms are forming the hydroxyls, our results show that there are $1.93 \mathrm{H}$ atoms per unit cell combined with $1.93 \mathrm{O}$ atoms which will result in the same amount of $\mathrm{OH}$. The composition at the 2a Wyckoff position in HAp was calculated to be: $(\mathrm{OH})_{2} \mathrm{O}_{0.07}$

The fact that the sites of the $\mathrm{O} 1, \mathrm{O} 2$ and $\mathrm{P}$ atoms show some vacancies, whereas the sites of $\mathrm{O} 3$ maintain significantly high occupancy, undoubtedly show evidence for replacement of $\mathrm{PO}_{4}{ }^{3-}$ by $\mathrm{CO}_{3}{ }^{2-}$ ions in the apatite lattice. Figure 3 shows the projection of the HAp structure on (001) plane. It reveals two types of tunnels (Type I and type II) which give it an ionic exchange property (substitution) either on calcium site or on the site of phosphorus and hydroxyl.
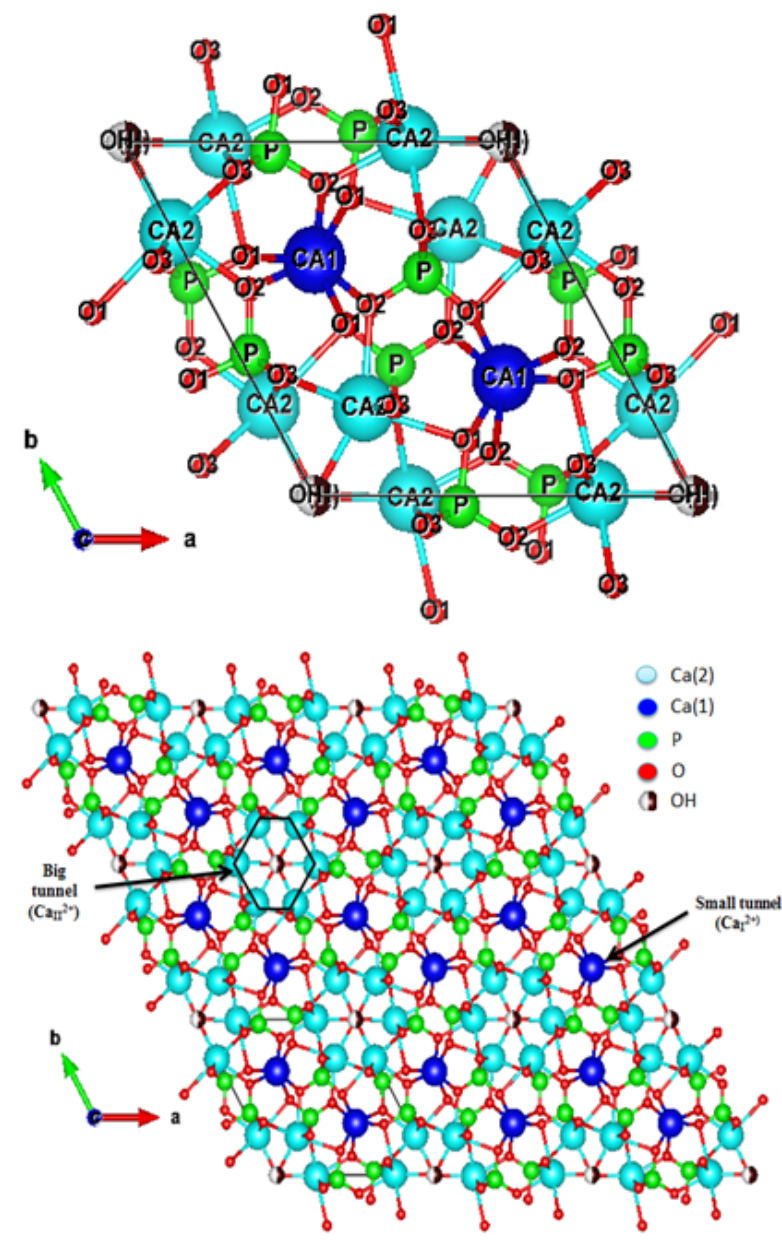

Figure 4. Projection of refined hydroxyapatite onto the (001) plane

\section{Conclusion}

A single-phase of HAp was prepared following an aqueous precipitation method. The XRD pattern suggests that the prepared sample has the hydroxyapatite characteristic structure, the FTIR spectra suggests the presence of HAp characteristic bands associated mainly to phosphate, hydroxyl and carbonate groups. The crystal structure was refined by the Rietveld analysis and revealed that HAp obtained is not pure hydroxyapatite but oxy-hydroxyapatite slightly carbonated $\mathrm{Ca}_{10}\left(\mathrm{PO}_{4}\right)_{6-\mathrm{x}}$ $\left(\mathrm{CO}_{3}\right)_{\mathrm{x}}(\mathrm{OH})_{\mathrm{y}} \mathrm{O}_{\mathrm{z}}$.

\section{References}

[1] E. Fujii, M. Ohkubo, K. Tsuru, S. Hayakawa, A. Osaka, K. Kawabata, C. Bonhomme and F. Babonneau, Acta. Biomater; 2, pp. 69-74, 2006.

[2] D.A. Puleo, L.A. Holleran, R.H. Doremus and R. Bizios, J. Biomed. Mater. Res. 25, pp. 711-723, 1991.

[3] R. Garcia and R.H. Doremus, J. Mater. Sci. Mater. Med. 3, pp. 154-156, 1992.

[4] K.J.L.Burg, S. Porter and J.F. Kellam, Biomaterials. 21, pp. 2342359, 2000.

[5] Y.J. Wang, J.D. Chen, K. Wei, S.H. Zhang and X.D. Wang, Mater. Lett. 60, pp. 3227-3231, 2006.

[6] C.S. Ciobanu, S.L. Iconaru, P. Le Coustumer, L.V. Constantin and D. Predoi, Nanoscale. Res. Lett. 7, pp. 324-332, 2012.

[7] G. Krishnamurithy, M. Raman Murali, M. Hamdi, A.A. Abbas, H.B. Raghavendran and T. Kamarul, Ceram. Int. 40, pp. 771-777, 2014.

[8] H. Yoshikawa, N. Tamai, T. Murase and A. Myoui, J. R. Soc. Interface. 6, pp. S341-S348, 2009.

[9] C.S. Ciobanu, F. Massuyeau, L.V. Constantin and D. Predoi, Nanoscale, Res. Lett. 6, pp. 613-620, 2011.

[10] C.S. Ciobanu, C.L. Popa and D. Predoi, J. Nanomater, pp. 1-9, 2014.

[11] C.S. Ciobanu, E. Andronescu and D. Predoi, Dig, J. Nanomater. Bios. 6, pp. 1239-1244, 2011.

[12] D.Predoi and R.A. Vatasescu-Balcan, J. Optoelectron. Adv. M. 10, pp. 152-157, 2008.

[13] Náray-Szabó, St, Zeit. Krist, 75, pp. 387-398, 1930.

[14] Mehmel, M, Zeit. Krist, 75, pp. 323-331, 1930.

[15] H.M. Kim, Current Opinion in Solid State and Materials Science 7, pp. 289-299, 2003.

[16] B. Chafik El Idrissi, K. Yamni, A. EL Yacoubi, A. Massit, IOSR Journal of Applied Chemistry, 2278 5736.Volume 7, Issue 5 Ver. III, pp. 107-112, May-2014.

[17] H.M. Rietveld, "Line profiles of neutron powder diffraction peaks for structure refinement,” Acta Crystallogr. 22, pp. 151-152, 1967.

[18] H.M. Rietveld, "A profile refinement method for nuclear and magnetic structures,” J. Appl. Crystallogr. 2, pp. 65-71, 1969.

[19] S.K. Pradhan, S. Bid, M. Gateshki, V. Petkov, "Microstructure characterization and cation distribution of nanocrystalline magnesium ferrite prepared by ball milling," Mater. Chem. Phys. 93, p. 224, 2005.

[20] S. Bid, S.K. Pradhan, "Preparation and microstructure characterization of ball-milled $\mathrm{ZrO} 2$ powder by the Rietveld method: monoclinic to cubicphase transformation without any additive,” J. Appl. Crystallogr. 35, p. 517., 2002.

[21] J. Rodríguez-Carvajal, Physica B 192, p. 55, 1993.

[22] R.A. Young, D.B. Wiles, “Application of the Rietveld methods for structure refinement with powder diffraction data," Adv X-ray Analysis 24, pp. 1-23, 1980.

[23] Gibson IR, Best SM, Bonfield W, "Chemical characterization of silicon-substituted hydroxyapatite,” J Biomed Mater Res, pp. 422-8, 44-1999.

[24] Kim SR, Riu DH, Lee YJ, Kim YH, "Synthesis and characterization of silicon substituted hydroxyapatite," Key Eng Mater, pp. 218-220: 85-8, 2002. 
[25] Rodriguez-Carvajal, “J. FULLPROF-A program for Rietveld, profile matching and integrated intensities refinement of X-ray and/or neutron data," Laboratoire Leon Brillouin: CEA-Saclay, France, 2000.

[26] A. Boultif and D. Louër, J. Appl. Crystal, Vol. 24, pp. 987-993, 1991.
[27] Daniel Arcos , Juan Rodríguez-Carvajal, Maria Vallet-Regí, Solid State Sciences 6, pp. 987-994, 2004.

[28] Th. Leventouri, C.E. Bunaciu, V. Perdikatsis, Biomaterials 24, pp. 4205-4211, 2003.

[29] P. Thompson, D.E. Cox, J.B. Hastings, J. Appl. Crystallogr. 20, p. $79,1987$. 